Gut, 1960, 1, 230.

\title{
A COMPARISON BETWEEN THE EFFECTS OF HEXAMETHONIUM AND ATROPINE IN COMBINATION AND OF VAGOTOMY WITH GASTROJEJUNOSTOMY ON HUMAN GASTRIC SECRETION
}

\author{
BY \\ J. MCARTHUR, * H. I. TANKEL, $\dagger$ and A. W. KAY $\ddagger$ \\ From the Western Infirmary, Glasgow, and the Royal Infirmary, Sheffield
}

This study records the gastric secretory response, using the Kay augmented histamine test, and compares "medical" vagotomy with atropine and hexamethonium with "surgical" vagotomy. The results suggest that it may be of value in predicting the effect of vagotomy with gastrojejunostomy.

The considerable difference of opinion which exists regarding the surgical treatment of duodenal ulcer suggests that the ideal operation has not yet been devised. The advantages of a lower morbidity rate with vagotomy and gastrojejunostomy compared with partial gastrectomy are offset by the higher incidence of recurrent ulceration in the former procedure (Cox and Kerr, 1957; Everson, Hutchings, Eisen, and Witanowski, 1957). It has been shown that the acid response to the augmented histamine test (Kay, 1953) is greater after vagotomy and gastrojejunostomy than after partial gastrectomy (Gillespie, Clark, Kay, and Tankel, 1960) and it seems possible that this may be responsible for the higher incidence of recurrent ulceration. However, the range of reduction in acid output which could be achieved was wide, and some patients after vagotomy with gastrojejunostomy exhibited acid reductions comparable to those achieved by partial gastrectomy.

It has been shown (Kay and Smith, 1956) that hexamethonium and atropine given in combination will inhibit spontaneous acid gastric secretion and motility through their acetylcholine blocking action. In this investigation we have compared the effect of hexamethonium and atropine with vagotomy and gastrojejunostomy on spontaneous and maximal gastric acid secretion, the latter being estimated by means of the augmented histamine test. It will be shown that significant correlations exist for maximal secretion. This raises the possibility that the effect

\footnotetext{
Present addresses:

*Dumfries and Galloway Royal Infirmary, Dumfries.

†Western Infirmary, Glasgow, W.1.

†Department of Surgery, Royal Infirmary, Sheffield, 6.
}

of hexamethonium and atropine on the augmented histamine response may be of value as a preoperative test by predicting the reduction in acidsecreting capacity which can be expected to result from vagotomy with gastrojejunostomy in the individual patient with duodenal ulceration.

\section{METHOD}

Twenty male patients with uncomplicated duodenal ulcer were selected for study. All were subsequently treated by subdiaphragmatic vagotomy with the addition of posterior gastrojejunostomy as the drainage procedure.

An augmented histamine test was carried out on at least two occasions before operation and once or twice after operation between the eighth and twelfth postoperative days.

In one pre-operative test in each patient the augmented histamine test was modified by the prior administration of hexamethonium and atropine in combination so that the acidity of spontaneous acid secretion was reduced to achlorhydria or to near-achlorhydria.

Each test was made after a 12-hour fast. A "neoplex" gastric tube was introduced through the nose and the stomach emptied by means of an electric suction apparatus. Complete aspiration of the gastric juice was achieved by frequently interrupting the suction and injecting a little air to ensure patency of the tube. Care was taken to standardize the tests for each subject by passing the tube to the same distance in each test.

In the augmented histamine tests the fasting juice was first aspirated and discarded. Specimens were then collected at 15-minute intervals for one hour to give one hour's spontaneous secretion. At the end of this period, $100 \mathrm{mg}$. mepyramine hydrogen maleate ("anthisan") was injected intramuscularly and the gastric juice collected in the subsequent $\mathbf{3 0}$ minutes was discarded. Histamine acid phosphate was then injected subcutaneously in a dose 
of $0.04 \mathrm{mg} . / \mathrm{kg}$. body weight and specimens collected at 15-minute intervals for a further 45 minutes. The last two specimens together were taken to represent the maximal histamine response.

In the modified tests, hexamethonium bromide, $50 \mathrm{mg}$., with atropine, $0.325 \mathrm{mg}$., was given as a single intramuscular injection after the fasting gastric juice had been aspirated. Thereafter, 15-minute specimens were taken for 75 minutes. The acid output in the last specimen was taken to represent the effect of the combination of drugs on the spontaneous secretion. Anthisan was now given and the test completed as a standard augmented histamine test.

Each specimen was measured for volume in millilitres, free acid (by titrating against $\mathrm{N} / 10 \mathrm{NaOH}$ with Töpfer's indicator), and the presence or absence of bile was also noted. The output of acid was expressed in milliequivalents $\mathrm{HCl}$ per half hour for both spontaneous secretion and the maximal histamine secretion. The percentage change due to hexamethonium and atropine and to vagotomy with gastrojejunostomy was then calculated for each patient. The means of these were calculated both arithmetically and geometrically, since the latter gives a more accurate estimation of the means of percentages than does the arithmetic mean. The regression equations were calculated to four decimal places and then rounded off to two decimal places.

In the following presentation, the use of hexamethonium and atropine will be referred to as "medical" vagotomy and that of vagotomy with gastrojejunostomy as "surgical" vagotomy.

\section{RESULTS}

Maximal Histamine Response: Acid OUtPut.The acid outputs in response to the augmented histamine test before and after "medical" and "surgical" vagotomy are shown in Table I. A reduction was effected in all cases after hexamethonium and atropine; the mean reduction was $37.3 \%$, which is statistically significant at the $1 \%$ level. Vagotomy with gastrojejunostomy likewise produced a reduction in the augmented histamine response in all cases, the mean reduction being $59.1 \%$ which is also statistically significant at the $1 \%$ level. This reduction was generally greater than that following hexamethonium and atropine and the difference between the two is also significant statistically. It will be noted that in patients Nos. 8, 9, and 19 the response to surgery was less than that due to "medical" vagotomy.

The volume outputs (Table II) after "medical" vagotomy show a mean reduction of $34.6 \%$ which is of the same order as the reduction in acid output (mean $37.3 \%$ ). However, the reduction in volume after operation (32.8\%) is proportionately very much less than the reduction in acid output $(59 \cdot 1 \%)$. This picture of a larger than expected volume after operation may be explained by reflux of bile and duodenal juice through the gastrojejunostomy stoma. However, more information can be obtained by examining the correlations between the sets of data.

Fig. 1 shows the acid outputs in response to the augmented histamine test after "medical" vagotomy (M) plotted against the simple augmented histamine outputs (P). There is a significant correlation between the two sets of data $(r=0.7930, P<0.01)$ and the regression of $P$ on $M$ is given by

$M=0.44 P+3.10$ (equation 1) (standard error of the estimate $= \pm 1 \cdot 89$ ).

TABLE I

EFFECT OF "MEDICAL" AND "SURGICAL" VAGOTOMY ON AUGMENTED HISTAMINE RESPONSE"

\begin{tabular}{|c|c|c|c|c|c|}
\hline $\begin{array}{c}\text { Patient } \\
\text { No. }\end{array}$ & $\begin{array}{c}\text { Before } \\
\text { Vagotomy } \\
\text { (P) }\end{array}$ & $\begin{array}{l}\text { After } \\
\text { "Medical" } \\
\text { Vagotomy } \\
\text { (M) }\end{array}$ & $\stackrel{\%}{\%}$ Reduction & $\begin{array}{c}\text { After } \\
\text { "Surgical" } \\
\text { Vagotomy } \\
\text { (S) }\end{array}$ & $\stackrel{\%}{\%}$ \\
\hline $\begin{array}{r}1 \\
2 \\
3 \\
4 \\
5 \\
6 \\
7 \\
8 \\
9 \\
10 \\
11 \\
12 \\
13 \\
14 \\
15 \\
16 \\
17 \\
18 \\
19 \\
20\end{array}$ & $\begin{array}{l}23.6 \\
17.8 \\
18 \cdot 1 \\
21.6 \\
16 \cdot 1 \\
10.6 \\
17 \cdot 3 \\
16 \cdot 1 \\
28.6 \\
30.7 \\
14 \cdot 0 \\
21.9 \\
23 \cdot 0 \\
16.6 \\
21.9 \\
13.1 \\
18 \cdot 7 \\
12.2 \\
17.6 \\
26.5\end{array}$ & $\begin{array}{r}13.6 \\
10.5 \\
11.0 \\
14.4 \\
8.5 \\
7.5 \\
14.5 \\
8.9 \\
15.7 \\
13.5 \\
7.6 \\
13.4 \\
13.5 \\
11.3 \\
16.5 \\
9.1 \\
13.1 \\
5.5 \\
11.6 \\
13.6\end{array}$ & $\begin{array}{l}42.4 \\
41.0 \\
39.2 \\
33 \cdot 3 \\
47.2 \\
29.2 \\
16 \cdot 2 \\
44 \cdot 7 \\
45 \cdot 1 \\
56.0 \\
45 \cdot 7 \\
38 \cdot 8 \\
41 \cdot 3 \\
31.9 \\
24 \cdot 7 \\
30.5 \\
30.0 \\
54.9 \\
34.1 \\
48.7\end{array}$ & $\begin{array}{r}6.3 \\
6.5 \\
6.4 \\
4.5 \\
5.0 \\
5.3 \\
11.8 \\
9.1 \\
17.7 \\
6.8 \\
2.0 \\
8.1 \\
7.7 \\
0.0 \\
9.9 \\
7.2 \\
7.6 \\
1.3 \\
12.1 \\
11.8\end{array}$ & $\begin{array}{r}73.3 \\
63.5 \\
64.6 \\
79.2 \\
68.9 \\
50.0 \\
31.8 \\
43.5 \\
38.1 \\
77.9 \\
85.7 \\
63.0 \\
66.5 \\
100.0 \\
54.8 \\
45.0 \\
59.4 \\
89.3 \\
31.2 \\
55.5\end{array}$ \\
\hline $\begin{array}{l}\text { Arithmetic mean } \\
\text { Geometric mean } \\
\pm \text { S.D. }\end{array}$ & $\frac{19 \cdot 30}{5 \cdot 56}$ & $\frac{11 \cdot 67}{3 \cdot 10}$ & $\begin{array}{c}38 \cdot 7 \\
37 \cdot 3 \\
-\end{array}$ & $\frac{7 \cdot 36}{4 \cdot 21}$ & $\begin{array}{c}62 \cdot 1 \\
59 \cdot 1 \\
-\end{array}$ \\
\hline
\end{tabular}

* Acid output is expressed in mEq./half hour. 
TABLE II

EFFECT OF "MEDICAL" AND "SURGICAL" VAGOTOMY ON AUGMENTED HISTAMINE RESPONSE*

\begin{tabular}{|c|c|c|c|c|c|}
\hline $\begin{array}{l}\text { Patient } \\
\text { No. }\end{array}$ & $\begin{array}{c}\text { Before } \\
\text { Vagotomy } \\
\text { (P) }\end{array}$ & $\begin{array}{l}\text { After "Medical" } \\
\text { Vagotomy } \\
\text { (M) }\end{array}$ & $\stackrel{\%}{\%}$ & $\begin{array}{l}\text { After “Surgical” } \\
\text { Vagotomy } \\
\text { (S) }\end{array}$ & Reduction \\
\hline $\begin{array}{r}1 \\
2 \\
3 \\
4 \\
5 \\
6 \\
7 \\
8 \\
9 \\
10 \\
11 \\
12 \\
13 \\
14 \\
15 \\
16 \\
17 \\
18 \\
19 \\
20\end{array}$ & $\begin{array}{l}195 \\
144 \\
142 \\
171 \\
148 \\
113 \\
144 \\
147 \\
228 \\
236 \\
123 \\
184 \\
186 \\
166 \\
205 \\
124 \\
163 \\
139 \\
147 \\
225\end{array}$ & $\begin{array}{r}113 \\
98 \\
99 \\
126 \\
80 \\
73 \\
134 \\
75 \\
124 \\
133 \\
68 \\
116 \\
117 \\
92 \\
151 \\
98 \\
99 \\
59 \\
103 \\
112\end{array}$ & $\begin{array}{r}42.0 \\
31.9 \\
30 \cdot 3 \\
26 \cdot 3 \\
45 \cdot 9 \\
35 \cdot 4 \\
6.9 \\
49 \cdot 0 \\
45 \cdot 6 \\
43.6 \\
44.7 \\
37 \cdot 0 \\
37 \cdot 1 \\
44 \cdot 6 \\
26.3 \\
21 \cdot 0 \\
39 \cdot 3 \\
57.6 \\
29.9 \\
50 \cdot 2\end{array}$ & $\begin{array}{r}97 \\
77 \\
131 \\
78 \\
62 \\
48 \\
123 \\
107 \\
160 \\
138 \\
66 \\
104 \\
124 \\
59 \\
114 \\
95 \\
152 \\
57 \\
125 \\
119\end{array}$ & $\begin{array}{r}50.3 \\
46.5 \\
7.7 \\
54.4 \\
58.1 \\
57.5 \\
14.6 \\
27.2 \\
29.8 \\
41.5 \\
46.3 \\
43.5 \\
33.3 \\
64.5 \\
44.4 \\
23.4 \\
6.7 \\
59.0 \\
15.0 \\
47.1\end{array}$ \\
\hline $\begin{array}{l}\text { Arithmetic mean } \\
\text { Geometric mean } \\
\pm \text { S.D. }\end{array}$ & $\frac{166 \cdot 5}{37 \cdot 3}$ & $\frac{103 \cdot 5}{\overline{25} \cdot 0}$ & $\begin{array}{c}37 \cdot 2 \\
34 \cdot 6 \\
-\end{array}$ & $\frac{101 \cdot 8}{34 \cdot 1}$ & $\begin{array}{l}38 \cdot 5 \\
32 \cdot 8 \\
-\end{array}$ \\
\hline
\end{tabular}

* Volume is expressed in $\mathrm{ml}$./half hour.

Similarly Fig. 1 also shows the post-operative outputs (S) plotted against the pre-operative outputs (P). The correlation is again significant $(r=0.5195 ; 0.02>P>0.01)$ and the regression of $\mathbf{S}$ on $\mathbf{P}$ is given by

$S=0.40 P-0.29$ (equation 2) (standard error of the estimate $\pm 3 \cdot 60$ ).

It is obvious by inspection of the equations that the two relationships are similar and that the difference between them is almost constant as is

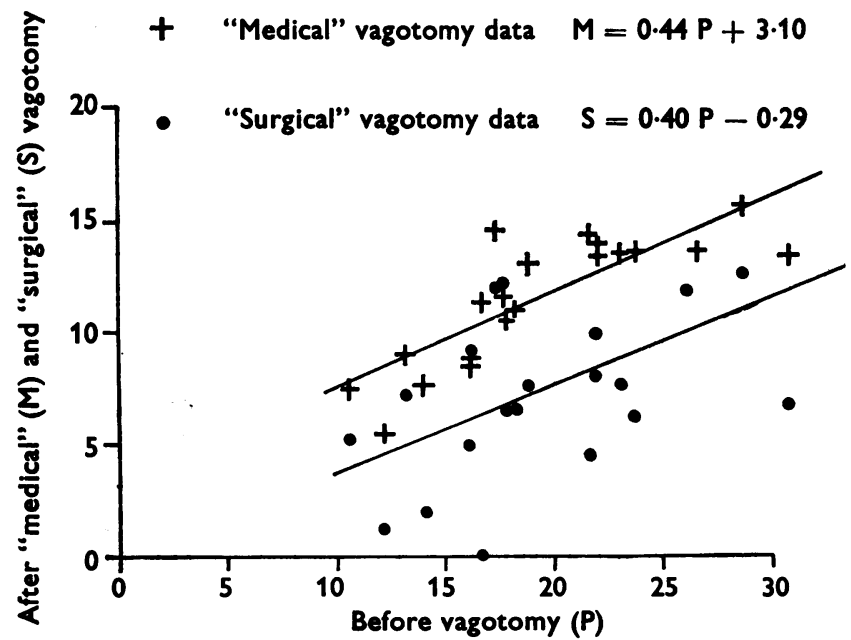

FIG. 1.-The correlations of the pre-operative data with "medical" vagotomy and with "surgical" vagotomy are shown (acid outputs in $\mathrm{mEq}$./half hour). The similarity between the two relationships can be clearly seen, the lines being almost parallel so that the differences at any point are almost constant. indicated by the fact that the lines on the graph are almost parallel. The regression coefficients 0.44 and 0.40 are not significantly different from each other $(t=0.50 ; 0.7>P>0.6)$ and suggest that "medical" vagotomy reduces the output by $56 \%$ while surgery reduces the output by $60 \%$ and that the difference between "medical" and "surgical" vagotomy resides mainly in the constants which are significantly different from each other $(t=8.04$; $\mathbf{P}<0.01)$.

When the actual individual differences between $M$ and $S$, i.e., the differences between "medical" and "surgical" vagotomy, are plotted against the corresponding values of $\mathbf{P}$ the regression equation is found to be

$$
M-S=4 \cdot 31+0.04(P-19 \cdot 3)
$$

and since $\mathbf{0 . 0 4}$ is a very small factor of $P$ and is not significantly different from zero, the equation may be reduced to

$$
M-S=4 \cdot 31 \text { (equation 3) }
$$

The same answer is obtained by subtracting equation 2 from equation 1 when allowance is made for rounding.

Thus by each of these methods the difference between "medical" (M) and "surgical" (S) vagotomy is shown to be a constant independent of $P$, the initial secretory activity of the stomach, and with a mean value of 4.31 .

Can the differences between "medical" vagotomy and "surgical" vagotomy be explained purely on the basis of the gastrojejunostomy stoma? 


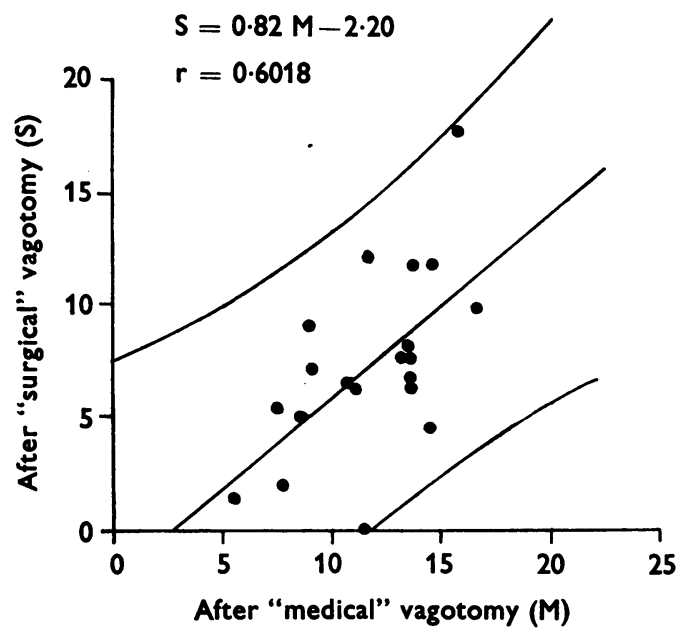

Fig. 2.-The relationship between the acid output responses to "medical" and "surgical" vagotomy with the corresponding $\mathbf{9 5 \%}$ confidence limits.

In a previous paper (Tankel, Gillespie, Clark, Kay, and McArthur, 1960) we have shown that there is a significant correlation between the preoperative acid outputs (P) and the outputs after simple gastrojejunostomy (G).

The relationship is given by the regression equation which was reduced to

$$
\mathrm{G}=1.03 \mathrm{P}-5.53
$$

$$
\mathbf{G}-\mathbf{P}=4.94^{*} \text { (equation 4) }
$$

and it was argued that the constant 4.94 was the mean loss in output due to a combination of neutralization by the passage of intestinal juice into the stomach and loss across the stoma, and was independent of the initial secretory activity of the stomach. If the difference between "medical" vagotomy and "surgical" vagotomy is the same as the difference between pre- and post-gastrojejunostomy then it would suggest that the difference between "medical" and "surgical" vagotomy is due solely to the presence of a gastrojejunostomy stoma. In fact, this is so, and the constant 4.31 is not significantly different from the constant 4.94 $(t=0.65 ; 0.6>P>0.5)$. Therefore, the difference between the responses to the augmented histamine test after "medical" vagotomy and after "surgical" are probably due solely to the effects of the gastrojejunostomy. However, this point can be approached more directly.

Fig. 2 shows the outputs after "medical"

\footnotetext{
-This is obtained as follows:-

$G=1.0345 P-5.5289$

$=P+0.0345 \times 17.0035-5.5289$

(Since the mean value of $P=17.0035$ )

$=P+0.5866-5.5289$

$=P+4.9423$.
}

vagotomy (M) plotted directly against the outputs after gastrojejunostomy with vagotomy (S). There is a significant correlation $(r=0.6018 ; P<0.01)$ and the regression of $M$ on $S$ is given

$\mathrm{S}=0.82 \mathrm{M}-2.20$ (equation 5) (standard error of the estimate $= \pm 3 \cdot 37$ ).

The factor 0.82 is not significantly different from $1.00(t=0.58 ; 0.6>P>0.5)$ and the equation can thus be reduced to

$$
S=M-4 \cdot 31
$$

since the mean value of $M=11.67$

$$
\text { or } \quad M-S=4.31 \text { (equation 6) }
$$

which is identical with equation 3 and helps to confirm the argument already outlined.

Maximal Histamine Response: Volume.Fig. 3 shows the volumes after "medical" vagotomy (M) plotted against the volumes of the pre-operative augmented histamine response (P). There is a significant correlation $(r=0.7048 ; P<0.01)$ between the two sets of data and the regression of $P$ on $\mathbf{M}$ is given by

$M=0.47 P+24.90$ (equation 7) (standard error of the estimate $= \pm 17 \cdot 73$ ).

Similarly Fig. 3 shows the volumes after "surgical" vagotomy (S) plotted against the pre-operative volumes (P). There is again a significant correlation $(r=0.5745 ; P<0.01)$ and the regression of $P$ on $S$ is given by

$S=0.52 P+14.54$ (equation 8) (standard error of the estimate $= \pm 27 \cdot 88$ )

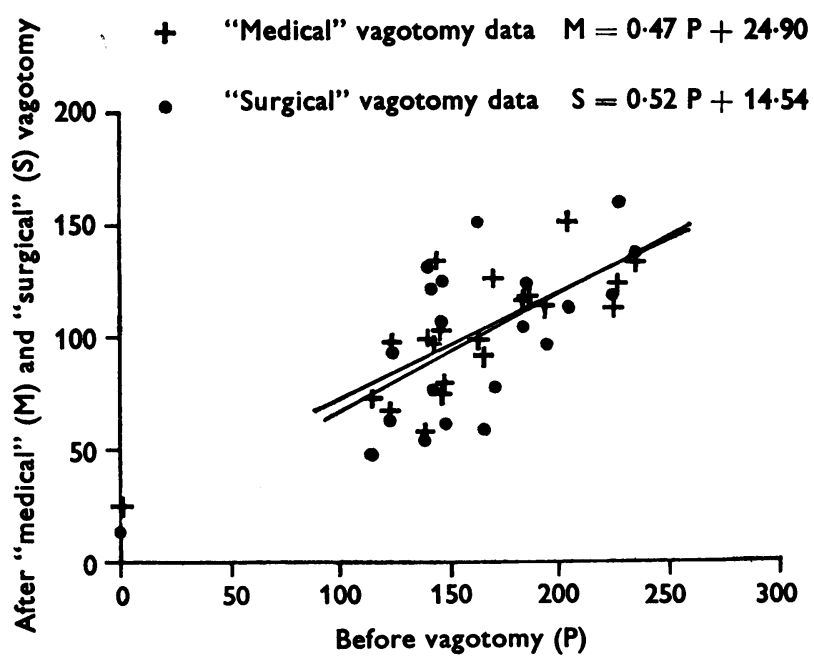

FIG. 3.-The correlations of the pre-operative data with "medical" vagotomy and with "surgical" vagotomy are shown (volumes in ml./half hour). There is a similarity between the two relationships and the lines are almost superimposed. 
Once again there is an obvious similarity between the two equations and, on the graph, the lines are almost superimposed. The regression coefficients 0.47 and 0.52 are not significantly different from each other $(\mathrm{t}=0.44 ; 0.7>P>0.6)$ and suggest that "medical" vagotomy causes a reduction of $53 \%$ and "surgical" vagotomy produces a reduction of $48 \%$ in the pre-operative volumes, with a further constant reduction of about $10 \mathrm{ml}$.

Again we may calculate the actual individual differences $(\mathbf{M}-\mathbf{S})$ and may compare them directly with the corresponding pre-operative volume $(\mathrm{P})$. The regression of $(\mathbf{M}-\mathbf{S})$ on $P$ is given by

$$
M-S=1.70-0.6(P-166.5)
$$

Since 0.06 is not significantly different from zero this becomes

$$
M-S=1 \cdot 70 \text { (equation 9) }
$$

This may also be obtained by subtracting equation 8 from equation 7. In our previous paper (Tankel et al., 1960) we have already shown that in the response to the augmented histamine test there is a significant correlation between pre-operative volume (P) and the volume after gastrojejunostomy $(G)$, the relationship being given by the equation

$$
\mathrm{G}=1 \cdot 23 \mathrm{P}-39 \cdot 21
$$

which was reduced to

$$
P-G=3.47 \text { (equation 10) }
$$

and there is no significant difference between the constants 3.47 and $1.70(t=0.23 ; 0.9>P>0.8)$. This suggests that gastrojejunostomy explains the difference between "medical" and "surgical" vagotomy as far as volume is concerned.

This point can also be approached more directly. Fig. 4 shows the volumes after "surgical" vagotomy

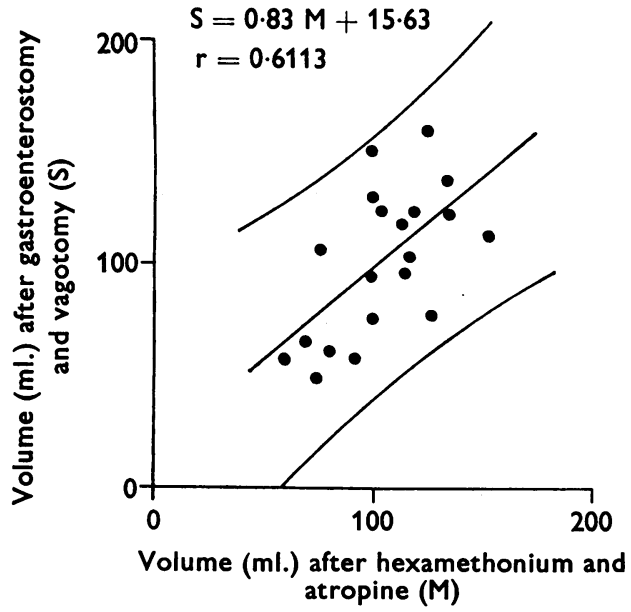

FIG. 4.-The relationship between the volume responses to "medical" and "surgical" vagotomy with the corresponding $95 \%$ confidence limits.
(S) plotted against the volumes following "medical" vagotomy (M). The correlation is significant $(r=0.6113 ; P<0.01)$ and the regression equation of $\mathrm{M}$ on $\mathrm{S}$ is given by

$S=0.83 \mathrm{M}+15.63$ (equation 11) (standard error of the estimate $= \pm 26.95$ ).

The correlation coefficient of 0.83 for volume is almost identical with the correlation coefficient of 0.82 for acid output, and, like it, is not significantly different from $1.00(\mathrm{t}=0.55 ; 0.6>\mathrm{P}>0.5)$. Proceeding on this assumption, therefore, the formula may be reduced to

$$
\mathbf{S}=\mathbf{M}-\mathbf{1 \cdot 7 0}
$$

or $\quad M-S=1 \cdot 70$ (equation 12)

which is identical with equation 9 which has already been deduced by a different method.

SPONTANEOUS SeCRETION.-Hexamethonium and atropine effect a gradual reduction in spontaneous secretion during the subsequent hour; achlorhydria resulted in 12 patients, and near achlorhydria in the remaining eight patients in the final 15-minute period (Table III). The final 15-minute period has, therefore, been taken to represent the effect of "medical" vagotomy on the spontaneous secretory rate. The mean reduction in the acid output is $98.7 \%$.

Following "surgical" vagotomy there was also a considerable and invariable reduction in the spontaneous acid output (mean $78.3 \%$ ) but in only seven patients did achlorhydria result, and in only two other patients was the level found to be as low as that produced after "medical" vagotomy. "Medical" vagotomy, therefore, produced a more profound reduction in the spontaneous acid gastric output than did "surgical" vagotomy, and this difference is statistically significant $(P<0.01)$.

When the volumes are considered (Table IV), there is an invariable drop in secretion following "medical" vagotomy but the volume was increased in 11 of the 20 patients after "surgical" vagotomy so that the mean difference was only $4.3 \%$. Since there is still a big reduction in acid output, the failure of "surgical" vagotomy to reduce the volume may be due to the reflux of bile and duodenal juice into the stomach. This is borne out by the fact that bile was present in the post-operative specimens of spontaneous secretion in 18 out of 20 patients.

The correlations between the pre-operative data $(P)$ and the "surgical" vagotomy data $(S)$ on the one hand and between the pre-operative data $(P)$ and the "medical" vagotomy data (M) on the other hand for both volume and acid output were not significant. This was due to the fact that volumes and acid outputs were reduced to such low levels after both "medical" and "surgical" vagotomy that measurement was difficult and the associated error high. 
TABLE III

EFFECT OF "MEDICAL" AND "SURGICAL" VAGOTOMY ON SPONTANEOUS SECRETION*

\begin{tabular}{|c|c|c|c|c|c|}
\hline $\begin{array}{c}\text { Patient } \\
\text { No. }\end{array}$ & $\begin{array}{l}\text { Before } \\
\text { Vagotomy } \\
\text { (P) }\end{array}$ & $\begin{array}{l}\text { After } \dagger \\
\text { "Medical" } \\
\text { Vagotomy } \\
\text { (M) }\end{array}$ & $\stackrel{\%}{\%}$ & $\begin{array}{l}\text { After } \\
\text { "Surgical" } \\
\text { Vagotomy } \\
\text { (S) }\end{array}$ & Reduction \\
\hline $\begin{array}{l}1 \\
2 \\
3 \\
4 \\
5 \\
6 \\
7 \\
8 \\
9 \\
10 \\
11 \\
12 \\
13 \\
14 \\
15 \\
16 \\
17 \\
18 \\
19 \\
20\end{array}$ & $\begin{array}{l}5.60 \\
1.88 \\
0.72 \\
3.13 \\
1.56 \\
0.94 \\
1.76 \\
1.61 \\
1.85 \\
4.82 \\
2.36 \\
3.45 \\
3.88 \\
2.73 \\
3.67 \\
4.73 \\
4.58 \\
0.69 \\
2.82 \\
4.70\end{array}$ & $\begin{array}{l}0.00 \\
0.02 \\
0.00 \\
0.17 \\
0.00 \\
0.00 \\
0.00 \\
0.00 \\
0.00 \\
0.00 \\
0.00 \\
0.05 \\
0.00 \\
0.13 \\
0.24 \\
0.09 \\
0.16 \\
0.00 \\
0.03 \\
0.00\end{array}$ & $\begin{array}{r}100 \cdot 0 \\
98.9 \\
100.0 \\
94.6 \\
100 \cdot 0 \\
100 \cdot 0 \\
100 \cdot 0 \\
100 \cdot 0 \\
100 \cdot 0 \\
100 \cdot 0 \\
100.0 \\
98.6 \\
100.0 \\
95.2 \\
93.5 \\
98 \cdot 1 \\
96.5 \\
100.0 \\
98.9 \\
100.0\end{array}$ & $\begin{array}{l}0.19 \\
1.27 \\
0.00 \\
0.39 \\
0.13 \\
0.00 \\
1.31 \\
0.92 \\
0.53 \\
0.48 \\
0.00 \\
0.01 \\
0.81 \\
0.00 \\
0.93 \\
0.00 \\
0.92 \\
0.00 \\
0.00 \\
0.43\end{array}$ & $\begin{array}{r}96.6 \\
32.4 \\
100.0 \\
87.5 \\
91 \cdot 7 \\
100.0 \\
25.6 \\
42.9 \\
71 \cdot 4 \\
90.0 \\
100.0 \\
99.7 \\
79.1 \\
100.0 \\
74.7 \\
100.0 \\
79.9 \\
100.0 \\
100.0 \\
90.9\end{array}$ \\
\hline $\begin{array}{l}\text { Arithmetic mean } \\
\text { Geometric mean } \\
\pm \text { S.D. }\end{array}$ & $\frac{2 \cdot 874}{1.54}$ & $\frac{0.044}{0.075}$ & $\begin{array}{c}98.7 \\
98.7 \\
-\end{array}$ & $\frac{0.42}{0.47}$ & $\begin{array}{c}83 \cdot 1 \\
78 \cdot 3 \\
-\end{array}$ \\
\hline
\end{tabular}

* Acid output is expressed in $\mathrm{mEq}$./half hour

+ Estimated on the secreting rate one hour after the injections of hexamethonium and atropine.

TABLE IV

EFFECT OF "MEDICAL" AND "SURGICAL" VAGOTOMY ON SPONTANEOUS SECRETION*

\begin{tabular}{|c|c|c|c|c|c|}
\hline $\begin{array}{l}\text { Patient } \\
\text { No. }\end{array}$ & $\begin{array}{c}\text { Before } \\
\text { Vagotomy } \\
\text { (P) }\end{array}$ & $\begin{array}{l}\text { Aftert } \\
\text { "Medical" } \\
\text { Vagotomy } \\
\text { (M) }\end{array}$ & Reduction & $\begin{array}{l}\text { After } \\
\text { "Surgical" } \\
\text { Vagotomy } \\
\text { (S) }\end{array}$ & Change \\
\hline $\begin{array}{r}1 \\
2 \\
3 \\
4 \\
5 \\
6 \\
7 \\
8 \\
9 \\
10 \\
11 \\
12 \\
13 \\
14 \\
15 \\
16 \\
17 \\
18 \\
19 \\
20\end{array}$ & $\begin{array}{l}69.5 \\
35.5 \\
29.0 \\
67.5 \\
37.5 \\
30.5 \\
58.0 \\
48.5 \\
36.0 \\
83.5 \\
52.0 \\
58.5 \\
53.5 \\
48.0 \\
73.5 \\
58.5 \\
73.5 \\
39.5 \\
58.5 \\
74.0\end{array}$ & $\begin{array}{r}3.0 \\
2.0 \\
1.0 \\
14.0 \\
1.0 \\
4.0 \\
1.0 \\
4.0 \\
6.0 \\
2.0 \\
1.0 \\
2.0 \\
12.0 \\
4.0 \\
20.0 \\
4.0 \\
5.0 \\
2.0 \\
2.0 \\
2.0\end{array}$ & $\begin{array}{l}95 \cdot 7 \\
94 \cdot 4 \\
96.6 \\
79.3 \\
97.3 \\
86.7 \\
98 \cdot 3 \\
91.8 \\
83.3 \\
97.6 \\
98.1 \\
96 \cdot 6 \\
77.6 \\
91.7 \\
72.8 \\
93.2 \\
93.2 \\
94 \cdot 9 \\
96.6 \\
97.3\end{array}$ & $\begin{array}{l}52.5 \\
40.5 \\
83.0 \\
36.0 \\
39.0 \\
35.5 \\
46.5 \\
68.5 \\
49.5 \\
81.5 \\
22.0 \\
21.5 \\
58.0 \\
62.5 \\
77.0 \\
57.5 \\
76.0 \\
66.5 \\
21.5 \\
36.0\end{array}$ & $\begin{array}{l}-24.5 \\
+14.1 \\
+186.2 \\
+46.7 \\
+\quad 4.0 \\
+18.3 \\
+19.8 \\
+41.2 \\
+37.5 \\
+2.4 \\
=57.7 \\
=63.2 \\
+\quad 8.4 \\
+30.2 \\
+\quad 4.8 \\
+\quad 1.7 \\
+\quad 3.4 \\
+68.4 \\
+63.2 \\
-51.4\end{array}$ \\
\hline $\begin{array}{l}\text { Arithmetic mean } \\
\text { Geometric mean } \\
\pm \text { S.D. }\end{array}$ & $\begin{array}{l}54 \cdot 2 \\
16 \cdot 58\end{array}$ & $\frac{4 \cdot 6}{5 \cdot 16}$ & $\begin{array}{l}91.7 \\
91.3 \\
-\end{array}$ & $\frac{51 \cdot 6}{20 \cdot 51}$ & $\begin{array}{l}+z^{4 \cdot 3} \\
-\end{array}$ \\
\hline
\end{tabular}

* Volume is expressed in $\mathrm{ml}$./half hour.

$\dagger$ Estimated on the secreting rate one hour after the injection of hexamethonium and atropine.

\section{Discussion}

Both "medical" vagotomy and "surgical" vagotomy have a profound inhibitory effect on the volume and the acid output of spontaneous secretion and the augmented histamine response.

As regards spontaneous secretion, this profound inhibition, which resulted in complete achlorhydria or near achlorhydria in all of the 20 patients after "medical" vagotomy and in nine patients after "surgical" vagotomy, was significant but precluded the demonstration of correlations.

However, significant correlations were obtained between the groups of responses to the augmented histamine test. It has already been argued from regression equations 1 and 2 that "surgical" vagotomy produces a reduction of $60 \%$ in acidity and "medical" vagotomy a reduction of $56 \%$, and that the differences between these percentages is not 
significant. We have also shown that the difference between "medical" and "surgical" vagotomy tends to be a constant, independent of gastric secretory activity and, in this study, was found to be $4.31 \mathrm{mEq}$. This value is not significantly different from the constant $4.94 \mathrm{mEq}$. previously calculated by us as being the effect of a simple gastrojejunostomy (Tankel et al., 1960). It has, therefore, been argued that the difference between "medical" and "surgical" vagotomy was due solely to the constant reduction produced by the gastrojejunostomy. Thus, the use of regression equations has enabled us to estimate the true reduction due to "surgical" vagotomy by allowing for the effect of the stoma.

Similarly we have shown from equations 7 and 8 that "surgical" vagotomy reduces the volume by $48 \%$ and "medical" vagotomy reduces it by $53 \%$, the difference between them once again being constant and independent of the secretory activity of the stomach.

This study was undertaken in order to compare the effect of "medical" vagotomy and of "surgical" vagotomy on the acid output and volume of the gastric secretion (Figs. 2 and 4). The $95 \%$ confidence limits are wide because of the degree of variations from individual to individual. However, the degree of correlation between the "medical" and "surgical" data raises the possibility that the effect of "medical" vagotomy on the augmented histamine response may be of value in predicting the effect of "surgical" vagotomy.
SUMMARY

A comparison has been made between the effect of hexamethonium and atropine and vagotomy with gastrojejunostomy on the volume and acid output of human gastric secretion. Significant correlations exist in response to the augmented histamine test though not for spontaneous secretion. This raises the possibility that the effect of hexamethonium and atropine on the augmented histamine response may be of value in predicting the effect of vagotomy with gastrojejunostomy.

We wish to express our thanks to Dr. R. A. Robb of the Mathematics Department, University of Glasgow, for his advice and criticism of the statistical methods employed in this study.

\section{REFERENCES}

Cox, H. T. and Kerr, D. F. (1957). Comparison of side-effects after partial gastrectomy and vagotomy and gastro-enterostomy. Brit. med. J., 1, 1211-1214.

Everson, T. C., Hutchings, V. Z., Eisen, J., and Witanowski, M. F. (1957). Partial gastrectomy versus vagotomy with gastroenterostomy in treatment of duodenal ulcer. A.M.A. Arch. Surg., 74, 547-554.

Gillespie, I. E., Clark, D. H., Kay, A. W., and Tankel, H. I. (1960). Effect of antrectomy, vagotomy with gastrojejunostomy; and antrectomy with vagotomy on the spontaneous and maximal gastric acid output in man. Gastroenterology, 38, 361-367

Kay, A. W. (1953). Effect of large doses of histamine on gastric secretion of $\mathrm{HCl}$ - an augmented histamine test. Brit. med.J., 2, 77-80.

- and Smith, A. N. (1956). The action of atropine and hexamethonium in combination on gastric secretion and motility. Brit. J. Pharmacol., 11, 231-235.

Tankel, H. I., Gillespie, I.' E., Clark, D. H., Kay, A. W., and McArthur, J. (1960). The effect of gastroenterostomy on human gastric secretion-a clinical and statistical study. Gut, 1, 223-229. 